NASA Technical Memorandum 88901

\title{
Surface Flaw Reliability Analysis of Ceramic Components With the SCARE Finite Element Postprocessor Program
}

John P. Gyekenyesi

Lewis Research Center

Cleveland, Ohio

and

Noel N. Nemeth

WLT Corporation

Cleveland, Ohio

Prepared for the

32nd International Gas Turbine Conference and Exhibit sponsored by the American Society of Mechanical Engineers Anaheim, California, May 31-June 4, 1987

\section{nush}




\section{GRGint FRGE FS OF POOR QUALTY}

SURFACE FLAW RELIABILITY ANALYSIS OF CERAMIC COMPONENTS WITH THE SCARE FINITE ELEMENT POSTPROCESSOR PROGRAM

John P. Gyekenyesi

National Aeronautics and Space Administration

Lewis Research Center

Cleveland, Ohio 44135

and

Noel N. Nemeth

WLT Corporation

Clevel and, Ohio 44142

\section{ABSTRACT}

The SCARE (Structural Ceramics Analys is and Reliability Evaluation) compute $\bar{r}$ program on statisticā fast fracture reliability analysis with quadratic elements for volume distributed imperfections is enhanced to include the use of linear finite elements and the capability of designing against concurrent surface flaw induced ceramic component failure. The SCARE code is presently coupled as a postprocessor to the MSC/NASTRAN general purpose, finite element analysis program. The improved version now includes the Weibull and Batdorf statistical failure theories for both surface and volume flaw based reliability analysis. The program uses the two-parameter weibull fracture strength cumulative failure probability distribution model with the principle of independent action for polyaxial stress states, and Batdorf's shear-sensitive as well as shearinsensitive statistical theories. The shear-sensitive surface crack configurations include the Griffith crack and Griffith notch geometries, using the total critical coplanar strain enerqy release rate criterion to predict mixed-mode fracture. Weibull material parameters based on both surface and volume flaw induced fracture can also be calculated from modulus of rupture bar tests, using the least squares method with known specimen geometry and grouped fracture data. The surface flaw reliability prediction uses MSC/NASTRAN stress, temperature, and external boundary area output, obtained from the use of linear or quadratic shell and three-dimensional isoparametric finite elements. The statistical fast fracture theories for surface flaw induced failure, along with selected input and output formats and options, are summarized. An example problem to demonstrate various features of the program is included.

\section{INTRODUCTION}

Brittle structures characteristically exhibit a large variation in fracture stress which must be taken into account in design. This variation in observed strength of nominally identical components is due to the presence of invisible material imperfections.
These imperfections are assumed to have a distribution in strength and the structure is assumed to fail when the strength of the weakest flaw or link is exceeded. Structural ceramics are known to contain at least two concurrent types of material imperfections or flaw populations. One type of unavoidable flaws arise from material processing, which are usually restricted to the interior of the structure and are referred to as volume or intrinsic flaws. Another flaw population with distinctly different structural response exists on the surface of a ceramic component. These external surface or extrinsic flaws can arise from grinding or other finishing operations, or maybe the result of environmental factors or of the intrinsic porosity intersecting the external surface. Statistical fast fracture models, based on weakest link theories (WLT) of Weibull, have been previously developed for both types of flaw populations (Weibull, 1939; Ruf in et al., 1984; Wertz and Heitman, 1980; Batdorf, 1978; Johnson, 1983). Recently, a pubi ic domain qeneral ourpose reliability code called SCARE has been generated (Gyekenyesi, 1986) to predict the fast fracture response of ceramic structures due to volume distributed flaws. It is the purpose of this paper to describe enhancements to the SCARE program which will allow reliability analys is with linear or quadratic elements of ceramic components due to the presence of a concurrent surface distributed flaw population. Consequently, fracture caused by either internal or external flaws can then be accounted for in the design process.

The first probabilistic method used to account for the scatter in fracture strength of brittle materials was introduced by Weibull (1939). His model was based on the weakest link theory and required certain statistical parameters to phenomenologically describe the failure response of a material. These statistical parameters were usually determined from uniaxially loaded, simple qeometry specimens. To predict material behavior in other stress states using statistical parameters from uniaxial tests, Weibull proposed calculating the risk of rupture by averaging the tensile normal stress in all directions. Since this approach is arbitrary and requires numerical modelina, other 
approaches were subsequently introduced. The most widely used of these is the principle of independent action (PIA) model, which is based on the assumption that the principal stresses act independently. The PIA fracture theory is the statistical version of the maximum stress failure theory, which was widely used in early metallic structure design. Most ceramic components in the government sponsored advanced gas turbine (AGT) programs used either or both of the above described polyaxial statistical failure models. Both of these fracture theories, however, can lead to unsafe estimates of failure (Gyekenyesi, 1986) since they both neglect the shear force, and in case of the PIA hypothesis, the effects of combined principal stresses.

In order to introduce a mechanistic fracture criterion into a statistically based analysis model to more accurately predict the nnset of catastrophic crack propagation, Batdorf developed a new theory which also applies to brittle materials in which the cracks are confined to the surface (Batdorf, 1973; Batdorf and Heinisch, 1978). He assumed that the cracks are randomly oriented, that they are perpendicular to the boundary and that they do not interact. The sizes of the cracks are not explicitly treated and fracture occurs when the remote macroscopic stress normal to the crack plane exceeds some critical stress, $\sigma_{\mathrm{cr}}$, characterizing that particular crack. Since the cracks are assumed normal to the surface, crack orientation is given by a single angular measure rather than two, as in the case of volume distributed flaws. This simplification is not always invoked (Shetty et al., 1984), although there is strong experimental evidence that it is justified (Batdorf, 1973).

In adding the influence of shear loading on the crack face, the external flaws are currently modeled as Griffith cracks and Griffith notches. Unlike with internal flaw analysis in SCARE, only the total criti$c$ al coplanar strain energy release rate, $G_{C}$, criterion is used to predict mixed-mode fracture (Samos, 1982), and the maximum tensile stress criterion, as described by Batdorf and Heinisch (1978), is not implemented for surface cracks in the program. It has also been concluded (Batdorf and Heinisch, 1978) that the Griffith crack is not an appropriate model of a typical surface imperfection, and is included here mainly for historical and for academic reasons.

Surface flaw based reliability analys is has been implemented in both the SCARE 1 and SCARE2 versions of the postprocessor program (Gyekenyesi, 1986). SCARE1 uses only elemental centroidal principal stresses to calculate reliability. In the SCARE2 version of the code, all linear or quadratic QUAD8 shell elements are further discretized into 9 subelements, which are then used with interpolated principal stresses to perform a) 1 analysis. In order to identify external boundaries, calculate their surface areas and obtain corresponding surface stress states, appropriate MSC/NASTRAN shell elements of negligible stiffness are used, together with the previously selected three-dimensional HEXA and PENTA elements. The selective use of shell elements permits the identification of only those external areas which contain potentially failurecausing flaws, and it can ignore boundaries from which fracture is not likely, such as finite element model symmetry planes or compressively loaded external surfaces.

\section{PROGRAM CAPABILITY AND DESCRIPTION}

The architecture and basic computational elements of the postprocessor program are described by Gyekenyesi (1986). Figure 1 shows the flowchart for the new surface flaw SCARE2 reliability analys is code, which is designed to be identical in its sequence of calculations to the previously developed volume flaw analvsis. For computational efficiency, all experimental fracture stresses as well as all elemental principal stresses are normalized. When using the Weibull scale parameter, $\sigma_{0}$, as the normalizing factor, it is important to note that different values of $\sigma_{0}$ are generally used in the volume and surface flaw calculations. For efficient transfer of MSC/NASTRAN output data to SCARE, FORTRAN logical units 3,4 , and 7 are used. Input to SCARE is handled through logical units 3,5 , and 7 while the output is stored on unit 1 .

Presently, the program permits use of several fracture criteria, crack confiqurations, and temperature dependent statistical material parameters. Uniaxial, surface flaw induced, fracture data alona with specimen geometry from four-point bend tests can be used to calculate Weihull parameters and the Batdorf flaw density coefficient. Fiqure? contains the available options in fracture criteria and flaw confiqurations used to model surface imperfections. Note that two of the failure criteria are for shear-insensitive cracks, even in multidimensional stress states. The other two are used for the shear-sensitive models, where the mechanistic $G_{C}$ fracture criterion is employed to predict component reliability. Among the a vailable criteria and crack configurations shown in Fig. 2, the Griffith notch with the $G_{c}$ criterion has the hiqhest shear-sensitivity and hence, the highest failure probability for a qiven structure, while the PIA approach yields consistently the lowest failure estimate. It should also be noted that the Batdorf shear-insensitive fracture model is conceptually identical to the oriqinally proposed Weibull normal stress averaqing method, although it has been recognized early that, when using this method, an amplification factor is required to accentuate the materials sensitivity to surface defects (Paluszny and Wu, 1977). No such factors, however, are used in the current version of the SCARE code.

In selecting thin shell elements to determine surface stress states, the existence of only two surface princioal stresses is intrinsic to the analysis. In order to use WLT, any compressive elemental principal stress is not permitted to exceed three times the tensile principal stress in ahsolute value. 0therwise, comoressive stress state predominates and the corresponding reliability is set equal to unity. Just like in uniaxial compressive loading, when using the PIA model with weibull statistics, fracture due to compression is inarmissible.

\section{INPUT INFORMATION}

The SCARE computer program requires output from MSC/NASTRAN elastostatic analys is to determine component fast fracture reliability. Gyekenyesi (1986) discusses some of the available rigid format solution sequence options and also how the NASTRAN and SCARE programs interface on the Lewis laboratory computer system. The surface flaw analys is capability uses only HEXA, PENTA, QUAD8, and TRIA6 MSC/NASTRAN library elements, and model ing with axisymetric elements is not permitted for external flaw reliability predictions. This restriction is due to NASTRAN finite element properties which rule out mixing of axisymmetric elements with any other element type in a qiven mesh. Only the HEXA and PENTA isoparametric elements should contribute to structural stiffness and the planar shell elements should have neqliqible thickness, $t$, specified in 


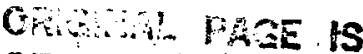 OF POOR QUALITY}

NASTRAN ( $t=10^{-6}$ in. for the rotating disk example in this paper). In addition to the previously listed reasons for using shell elements, modeling a ceramic structure with them will also avoid the need for elemental stress transformations when calculating required suriace principai siresses. Fur avaijaile siress recovery options, users should consult the appropriate analys is code manuals. With today's automatic mesh generation programs, little difficulty will be encountered in adding the required external elements. A solid element face is identified as an external sur$f$ ace when its nodes are shared by a shell element. The midside nodes may or may rot be present, but current capability requires that either they are all there consistently, or they are all absent. Mixing of linear or quadratic elements in a given finite element mesh is not permitted. When using shell elements, only the membrane properties should be invoked and the uncoupled bending stiffness should not be included in the model.

SCARE input requirements for external flaw analysis are almost identical to the input data for internal flaw analysis, which has been previously summarized (Gyekenyesi, 1986). The postprocessor program is capable of doing the volume and surface flaw analys is in one execution. However, only the surface distributed crack capability will be described in this paper. As before, program input can be grouped into three categories. The first category, shown in Fig. 3 , is called the master control deck, which includes organization of control indices for fracture criteria, finite element model requirements, and material parameter format. Note that for calculating statistical parameters, data only from four-point bend test can currently be used. In addition, two-lines or cards of data entry are now required rather than one as in the previous volume flaw analysis. The fracture criteria and flaw shapes for representing volume and surface imperfections can be independently specified, and users can select to perform analysis for volume flaw based fracture only, for surface flaw based fracture only, or for both simultaneously in one execution. Details on included options and limitations $c$ an be found in the program user's manual.

The second category, called the specimen deck, uses fracture specimen data required in calculating statistical fracture parameters, or direct input of material properties including Poisson's ratio. These material parameters are generally temperature dependent. Therefore, provision is made for input of multiple flaw populations at different temperatures. Unless material parameters are directly read, this section requires four-point bend bar geometry and surface flaw based failure stresses of the sample population. These extreme fiber failure stresses must be arranged in ascending order and currently up to 200 specimens can be used for a given temperatıre. The specimen deck also requires test temperatures, arranged in ascending order for multiple temperatures, since calculated material parameters are interpolated within SCARE. At a specified temperature, fracture stresses must be unique and multiple values of identical magnitudes are not permitted. The number of available fracture readings for all temperature tests must be the same. Additional explanation of the required input, including size limitations, can be found in the user's manual.

The last SCARE input category, called the structures deck, contains results of the finite element structural analysis required for failure probability predictions. These include solid element volumes, shell element areas, nodal temperatures (MSC/NASTRAN does not permit access to element temperatures), ele- mental principal stresses and corresponding element identification numbers. In the present version of SCARE, which relies on MSC/NASTRAN output files, al of this data is internally manipulated through subroutine ELEM, and the structures deck requires no specific input by the uscir.

\section{OUTPUT INFORMATION}

Grid point temperatures in a finite element mesh of a selected component $c$ an be obtained at transient or steady state conditions from performing MSC/NASTRAN thermal analysis. Combining the resulting thermal loads with additional mechanical loads, the displacement and elastic stress fields can then be calculated. For surface flaw based fracture analysis, shell element stresses, areas and temperatures are the required output from the analysis code. For available output options, users should consult the appropriate program manuals. The shell element stresses as well as the nodal temperatures from MSC/NASTRAN are stored in specified punch files, while surface element areas are listed in the proqram output file. Consequently, NASTRAN's punch option must be invoked to store the required stress and temperature data with the program's parameter call feature needed to calculate the required elemental areas.

The first part of all SCARE output data contains an echo of important NASTRAN finite element analys is results. Identifying labels, element type, and number of elements in the model are noted. Since in a large finite element mesh the stress output could be excessive, printed element stress tables in the new version of SCARE are optional as shown in Fiq. 3. In addition, two new element cross-reference tables are printed. The first table lists the shell element number and gives the corresponding solid element with which its grid points are shared. The second table lists the solid element identification number and gives up to six associated shell elements (a HEXA element could have all of its six faces as an external surface). Element areas and temperatures (nodal averaged) are summarized in the following table. Next the selected fracture model is identified and the room temperature statistical fracture parameters are shown. Additionally, a table of discrete input temperatures with corresponding material parameters, which were either internally calculated or directly supplied, is printed. For the shear-sensitive fracture models, the crack shape is identified along with a more specific description of the fracture criterion. The last table in the SCARE output file contains an element results summary, listing the shell element number, corresponding element survival and failure probabilities, and interpolated (based on temperature) element material parameters. Finally, the overall component probability of failure as well as the component probability of survival are printed.

THEORY

The most widely used mathematical models describing the statistical nature of fracture in brittle materials have been previously summarized by Gyekenyesi (1986). It is generally recognized that the weakest link hypothesis and the two-parameter weibull cumulative strength distribution are appropriate to modeling surface flaw induced failure in ceramic structures. Consequently, the uniaxial fracture data is approximated by 


$$
P_{f s}=1-\exp \left[-\int_{A}\left(\frac{\sigma_{s}}{\sigma_{o s}}\right)^{m_{s}} d A\right]
$$

where the subscript $s$ denotes parameters associated with the surface, $P_{f s}$ is the cumulative failure probability, $\sigma_{0}$ is the scale parameter with dimensions of stress $x$ (area $)^{1 / m_{s}}, m_{s}$ is the Weibull modulus which measures the degree of variability, os is the applied surface tensile stress, and $A$ the stressed area. The scale parameter is often called the unit area characteristic strength, and as $m_{s}$ increases it approaches the material's ultimate strength. The selectively used Weibull threshold stress parameter, $\sigma_{u s,}$, is taken to be zero in $\mathrm{Eq}$. (1) and is not shown therein.

In the analysis of failure of brittle materials subject to multiaxial stress states, the weibull model, when combined with the PIA hypothesis, yields

$$
P_{f s}=1-\exp \left\{-\int_{A}\left[\left(\frac{\sigma_{1 s}}{\sigma_{0 s}}\right)^{m} s+\left(\frac{\sigma_{2 s}}{\sigma_{0 s}}\right)^{m_{s}}\right] d A\right\}
$$

where $\sigma_{1} \mathrm{~s}$ and $\sigma_{2}$ s are the principal in-plane stresses acting on the surface of the structure. Equation (2) has been widely used in the past to estimate failure probabilities of ceramic components (Wertz and Heitman, 1980). The failure probability using the normal stress averaging method, as extended to surface distributed flaw problems, can be calculated from

$$
P_{f s}=1-\exp \left\{-\int\left[k_{A p s} \int_{C}^{\sigma_{n s}} d C\right] d A\right\}
$$

where $k_{w p s}$ is the polyaxial Weibull crack density coefficient for surface flaws. This constant can be obtained by making the result of integrating Eq. (3), using the normal stress ons distribution on an arbitrary plane, obtained from the reduced, planestress Cauchy infinitesimal tetrahedron in principal stress space as shown in Fig. 4, for uniaxial stress cases, agree with the results obtained from the uniaxial, two-parameter Weibull equation. Unlike for volume flaw based analys is where closed form integration is possible, the polyaxial Weibull surface crack density coefficient must be evaluated numerically. The contour integration is performed on the circumference of the unit circle $C$ where the normal stress is tensile and neglecting regions where the normal stress is compressive. The crack-like flaws can then be regarded as located in these arbitrary planes which are tangent to the unit circle and are acted upon by ons which is induced by the principal stresses ols and o.s. Since $\mathrm{Eq}$. (3) is just the shear-insensitive case of the more general Batdorf polyaxial stress fracture model, its SCARE implementation follows a somewhat different format. The polyaxial Weibull equation has also been selectively used in the past (Paluszny and Wu, 1977), but since it neglects the effects of shear loads, it also underestimates failure for the more general loading condition. These unconservative predictions have been recognized early in ceramic structures and the use of amplification factors was proposed to better correlate predictions with measurements.
In the previously described two multidimensional stress fracture models, no mechanistic fracture criterion was needed to predict impending failure. In prior work by Batdorf (1973), Batdorf and Heinisch (1978), Shetty et al., (1984), and Samos (1982), attention is focused on cracks and their failure under stress. Since there is yet no consensus regarding how to treat mixed-mode fracture, even in metallic structures, the SCARE program includes several fracture criteria and flaw shapes. These criteria and flaw configurations include those traditionally treated, although recent research in ceramic fracture emphasizes more advanced fracture criteria and better modeling of flaw shapes (Petrovic, 1985).

Consider now a small uniformly stressed material element of area $\Delta A$. The probability of failure under an applied state of stress can be written as

$$
P_{f s}=P_{1 s} P_{2 s}
$$

where $P_{1 s}$ is the probability of existence in $\Delta A$ of a crack having a critical stress in the range of $\sigma_{c r}$ to $\sigma_{c r}+d \sigma_{c r}$, and $P_{2 s}$ denotes the probability that a crack of critical stress $\sigma_{\mathrm{cr}}$ will be oriented in a direction such that an effective stress aes equals or exceeds ${ }^{\circ} \mathrm{cr}$. $\sigma_{\mathrm{cr}}$ is defined as the remote, uniaxial, normal fracture stress of a given crack. Failure will occur when the effective stress (a function of chosen crack configuration and fracture criterion) exceeds $\sigma_{\mathrm{cr}}$ for a particular crack. $\mathrm{P}_{1 \mathrm{~s}}$ has the form

$$
P_{1 s}=\Delta A \frac{d N_{s}}{d \sigma} d \sigma_{c r}
$$

and

$$
P_{2 s}=\frac{\omega}{\pi}
$$

where $N_{S}\left(\sigma_{C r}\right)$ is the surface crack density function (the density of cracks having a critical stress $\leq \sigma_{c r}$ ) and $\omega$ is the angle in principal stress space containing all the crack orientations for which $\sigma_{e s}>\sigma_{\mathrm{cr}}$. Using the weakest link theory, the overall faiTure probability can be calculated from (Samos, 1982)

$$
P_{f s}=1-\exp \left[-\int_{A} d A \int_{0}^{\sigma} 1 s \quad\left(\frac{\omega}{\pi}\right) \frac{d N_{s}}{d \sigma_{c r}} d \sigma_{c r}\right]
$$

The surface crack density function $N_{S}\left(\sigma_{c r}\right)$ is a material property which is expected to be of Weibul form since it is directly the cause of the observed Weibull strength distribution. However, for values of $m_{s} \gg 1.0$, and assuming that 1 arge number of cracks are sampled, that is $\sigma_{\mathrm{cr}} \ll \sigma_{0 s^{A}}{ }^{-1 / m_{s}}$, the Weibull distribution can be approximated by a power function, leading to

$$
\mathrm{N}_{s}\left({ }_{\mathrm{c}} \mathrm{cr}\right)=\mathrm{k}_{\mathrm{Bs}}{ }^{\mathrm{m}}{ }_{\mathrm{c}}^{\mathrm{cr}}
$$

The surface flaw distribution parameters $k_{B s}$ and $m_{S} c a n$ be evaluated from experimental data using uniaxial specimens and an appropriate fracture criterion. Since cracks in a real material are assumed to have an equal likelihood of orientation, and it is 


\section{ORIGWAR PAGE IS
OF POOR QUALITY}

believed that there are so many cracks present that there is always one crack with the least-favorable orientation and that crack growth from this flaw causes failure, mode I fracture is intrinsic to uniaxial loading and the critical normal stress fracture criterion

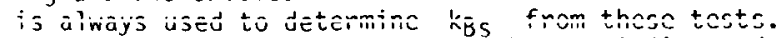
However, finishing operations such as grinding and environmental damage from erosion or oxidation may lead to anisotropic surface conditions, which then must be carefully accounted for in material characterization. it is important to note that the use of various mixed-mode fracture criteria to evaluate $k_{B s}$ from uniaxially loaded specimens will result in different corresponding values of this flaw density parameter, from which it follows that the component reliability predictions will also change (Shetty et al., 1984). In fact the use of an identical mixed-mode fracture criterion to evaluate $k_{B S}$ from MOR bars first, and then subsequently calculate multiaxially loaded component reliability with it will result in contradictory trends, where with increased shear-sensitivity, component failure rate predictions will decrease. In the present version of SCARE, failure rate predictions increase with increasing shear-sensitivity, which follows from always assuming mode I fracture in uniaxial tests. Limited experimental data with monolithic ceramics (Samos, 1982) tend to validate the present approach, and the need for more pessimistic failure predictions than those obtained from the early phenomenological models is evident from component test records.

The statistical analysis of fracture is greatly simplified by assuming that cracks are shearinsensitive. For this case fracture occurs when $\sigma_{e s}=\sigma_{n s}>\sigma_{\mathrm{cr}}$ and there is no need to specify the crack shape or the materials Poisson's ratio. The effective stress just equals the normal stress acting on the crack plane.

When cracks are shear-sensitive, equations for oes using various fracture criteria can be derived by equating selected parameters, induced by a uniaxial normal stress acting on a specified crack shape, to the selected parameters calculated for the mixed-mode or multiaxially loaded identical crack configuration. Some of the most widely used parameters to predict impending failure include the total coplanar strain energy release rate or crack extension force $G_{C}$, the maximum strain energy release rate $G_{\max }$, the minimum strain energy density $S_{C}$, the normal stres $s$ $\sigma_{n s}$, and the maximum tangential or hoop stress $\sigma_{\theta \theta}$. The $G_{\max }, S_{C}$, and $\sigma_{\theta \theta}$ fracture parameters predict out-of-plane crack extension, and consequently, are believed to be the most accurate for mixed-mode crack propagation. In any event, for polyaxial stress states, the effective stress $\sigma$ es is a function of both $\sigma_{n s}$ and $\tau_{s}$ where $\tau_{s}$ is the shear stress in the crack plane. Both ons and $\tau_{s}$, acting on a plane whose normal and the maximum principal stress direction form an angle $\alpha$, can be calculated from considering the equilibrium of forces in Fig. 4. Summing forces in the normal and tangentical directions gives, respectively

$$
\begin{aligned}
& \sigma_{n s}=\sigma_{1 s} \cos ^{2} \alpha+\sigma_{2 s} \sin ^{2} \alpha \\
& { }_{s}=\left(\sigma_{1 s}-\sigma_{2 s}\right) \cos \alpha \sin \alpha
\end{aligned}
$$

Using the $G_{C}$ criterion and the two selected crack configurations, the effective stress equations obtained are (Samos, 1982)

$$
\begin{gathered}
\sigma_{e s}=\sqrt{\sigma_{n s}^{2}+T_{s}^{2}} \quad \text { (Griffith crack) } \\
\sigma_{\text {es }}-\sqrt{r_{n s}^{2}+\frac{1}{1-v}\left(\frac{S_{s}}{1.1215}\right)^{2}} \text { (Eriffith nntch) }
\end{gathered}
$$

where $v$ is Poisson's ratio and $S_{S}$ is the out-ofplane shear stress since $\tau^{\prime}$ does not cause crack growth in a Griffith notch. In general, the total coplanar strain energy release rate can be expressed in terms of stress intensity factors, summing damage in a 11 appropriate crack growth modes. From equality of cross-shears, $S_{S}=\tau_{S}$ and Eq. (9) can be used

to evaluate $\sigma_{e}$ for both cracks.

The angle ${ }^{2}$ depends on the fracture criterion selected, the assumed crack configuration and on the applied stress state. Closed form expressions for $\omega$ can be derived for some fracture criteria in uniaxial and equibiaxial stress states (Samos, 1982). Assuming a uniaxial stress $\sigma_{1 s}=\sigma_{5}$, and the normal stress (shear-insensitive) fracture criterion, we obtain from

Eq. (9) at $\sigma_{n s}=\sigma_{c r}, \alpha=\alpha_{c r}$, and $\omega=2 \alpha_{c r}$ that

$$
\frac{\omega}{\pi}=\frac{2}{\pi} \cos ^{-1} \sqrt{\frac{\sigma_{c r}}{\sigma_{s}}}
$$

Note that when a shear-sensitive fracture criterion is used, the crack shape must also be specified. In general, for two-dimensional stress states, $\omega$ must be determined numerically. Using the shear-insensitive case as an example, we obtain at fracture

$$
\begin{aligned}
\sigma_{e s} & =\sigma_{n s}=\sigma_{c r}=\sigma_{1 s} \cos ^{2} \alpha_{c r} \\
& +\sigma_{2 s} \sin ^{2} \alpha_{c r}
\end{aligned}
$$

If we define $K=\sigma 2 s / \sigma 1 s$ and we note that $\alpha_{\mathrm{cr}}=\omega / 2$, Eq. (12) yields

$$
P_{2 s}=\frac{\omega}{\pi}=\frac{2}{\pi} \cos ^{-1}\left[\frac{\left(\frac{\sigma_{c r}}{\sigma_{1 s}}\right)-k}{1-K}\right]^{1 / 2}
$$

In order to avoid singular conditions $\left(\sigma_{1 s}=\sigma_{25}\right)$ in Eq. (13), the following constraints must be imposed in calculating $P_{2 s}$ :

$$
\begin{aligned}
& \text { if }\left(\sigma_{\mathrm{cr}} / \sigma_{1 \mathrm{~s}}-K\right) /(1-K)<0.0 \text { then } \omega=\pi \\
& \text { if }\left(\sigma_{\mathrm{cr}} / \sigma_{1 \mathrm{~s}}-K\right) /(1-K)>1.0 \text { then } \omega=0 \\
& \text { if } K=1.0 \text { then }\left\{\begin{array}{l}
\omega=\pi \text { if } \sigma_{1 \mathrm{~s}} \geq \sigma_{\mathrm{cr}} \\
\omega=0 \text { if } \sigma_{1 \mathrm{~s}}<\sigma_{\mathrm{cr}}
\end{array}\right.
\end{aligned}
$$

A similar procedure can be followed for the shearsensitive Griffith crack using both of $\mathrm{Eq}$. (9) in Eq. (10). However, for the Griffith notch it is computationaliy convenient to define $\phi=\cos ^{2} \alpha_{\mathrm{cr}}$, so that the fracture condition $\sigma_{\mathrm{es}} \geq{ }^{\sigma} \mathrm{cr}$ can be written as (Samos, 1982)

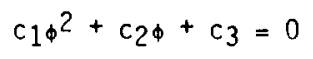


Solving for $\phi$ gives

$$
\phi=\cos ^{2} \alpha_{c r}=\frac{-c_{2} \pm \sqrt{c_{2}^{2}-4 c_{1} c_{3}}}{2 c_{1}}
$$

where

$$
\begin{aligned}
& c_{1}=(1-k)^{2}\left(1-\frac{0.795}{1-v}\right) \\
& c_{2}=(1-k)\left[2 k+(1-k) \frac{0.795}{1-v}\right] \\
& c_{3}=k^{2}-\left(\frac{\sigma_{c r}}{\sigma_{1 s}}\right)^{2}
\end{aligned}
$$

From Eq. (15), $\alpha_{\mathrm{cr}}=\cos ^{-1} \sqrt{4}$. Consequently,

$$
\frac{\omega}{\pi}=\frac{2}{\pi} \alpha_{c r}=\frac{2}{\pi} \cos ^{-1}\left[\frac{-c_{2} \pm \sqrt{c_{2}^{2}-{ }^{4 c_{1} c_{3}}}}{2 c_{1}}\right]^{1 / 2}
$$

Following an analogous procedure to the above in using fracture criteria and flaw shapes, similar expressions for $P_{2 s}$ in terms of principal stresses and $\sigma_{\mathrm{cr}}$ can be developed. Results of this analys is are summarized in Table I and details are given by Samos (1982). In addition, special stress states such as the equibiaxial loading case where $K=1.0$ and when Eq. (17) becomes singular, are treated.

The equations in Table I apply only when ons is tensile. When a compressive normal stress state exists, the angle where the normal stress changes from tensile to compressive is calculated. This transition angle divides all possible crack orientations into a tensile normal stress region and a compressive norma? stress region, where each region has a different effective stress equation. In the compressive stress reqion $\sigma_{n s}$ is set equal to zero, and with friction between crack faces ignored, ofes is a function of only the applied shear load. In each reqion, the anqle at which $\sigma_{\text {es }}=\sigma \mathrm{cr}$ is calculated. This angle further divides the region into areas where $\sigma_{e s} \geq \sigma_{\mathrm{cr}}$ and $\sigma_{e s}<\sigma_{\mathrm{cr}}$. If there is no such angle within the qiven region, then either there is no contribution to $\omega$ from that reqion or the entire region is included. A calculation comparing $\sigma_{e s}$ to $\sigma_{c r}$ for a selected angle $\alpha$ identifies which subregion, or whether the whole region, contributes to $\omega$. After determining each $w$ from the tensile and compressive regions separately, the total angle $\omega$ is simply the sum of the two contributions.

An alternate approach to calculating $P_{2 s}$ has also been previously developed, where the angle $\alpha$ is incremented over the unit circle, and at each discrete point the contribution of ons or $\sigma_{\text {es }}$ is summed depending on whether they are equal or greater than $\sigma_{\mathrm{Cr}}$. Since $\sigma_{\mathrm{Cr}}$ is always positive, compressive ons or $\sigma_{e s}$ will never contribute to fracture. The same method can also be used in volume flaw based failure analysis, where two angles must be incremented so that the stresses are checked at all points on the unit sphere. This procedure, when compared to the previous method used to calculate $P_{2 s}$, is computationally much more intensive. Consequently, SCARE employs the more efficient approach and the equations summarized in Table I are coded to calculate critical crack orientations.

In the SCARE program the required integration is performed by using Gaussian auadratures. Employing the power function form of $\mathrm{N}_{S}\left(\sigma_{\mathrm{Cr}}\right)$ and the appropriate equation for $P_{2 s}$ in Eq. (7), the failure probability using the Batdorf approach for surface flaws can be calculated. Unlike for volume flaw analys is where a double numerical integration is generally required, surface flaw analysis uses only a single integration for the critical stress. Assuming that the stress state is constant in any aiven shell element (SCARE1 version) or subelement (SCARE2 version), the area integration over the material surface becomes trivial. For component reliability analysis, the elemental survival probabilities are summed according to established probability axioms, that is, we evaluate the product of all the individual, constant stress state elemental reliabilities. For two mutually exclusive events, such as the calculation of $P_{f s}$ and $P_{s s}$, it is well known that for a given area increment their sum is always unity, where $P_{S S}$ denotes surface survival probability. Finally, if a component includes two concurrent modes of possible failure, such as due to simultaneous internal or external flaws, its total reliability can be determined from the product of its individual cause reliabilities.

\section{MATERIAL STRENGTH CHARACTERIZATION}

Uniaxial ceramic strength data is usually obtained from flexure testing simple geometry specimens, and recording the extreme fiber tensile stress in the most highly loaded area at fracture. The Weibull parameters $\sigma_{0 S}$ and $m_{S}$ as well as the Batdorf flaw density paramenter $k_{B S}$ are evaluated in SCARE using fourpoint MOR data with known genmetry. Fracture is sometimes assumed to always occur between the symmetrically placed inner loads on the tensile side (Samos, 1982), but in SCARE an effective area is used which permits failure in any tensile loaded areal element of the bar (Govila, 1983). It should be noted that for uniaxial tensile loading the effective area $A_{e}$ reduces to $A$, the specimen gauge surface area. In all other types of loading, $A_{e}$ is a function of specimen geometry and material Weibull modulus. If we express the uniaxial flexure failure probability in terms of the maximum extreme fiber fracture stress of or MOR using Weibull form, that is

$$
P_{f s}=1-\exp \left[-c_{s}^{m_{s}}{ }^{m}\right]
$$

then after evaluating $C_{S}$ and $m_{S}$ by the leastsquares method, $\sigma_{0 S}$ and $k_{B S}$ can be calculated. Using the effective area for a rectangular beam in four-point bending (Govila, 1983)

$$
A_{e}=\left\{\left[\frac{\left(\frac{L_{2}}{L_{1}}\right) m_{s}+1}{2\left(m_{s}+1\right)^{2}}\right]\left(\frac{m_{s} w}{w+h}+1\right)\right\} 2 L_{1}(h+w)
$$

where $L_{1}$ is the length between the outer loads, $L$ ? is the length between the inner loads, $w$ is the beam width, and $h$ is the beam height, we can rewrite Eq. (1) as

$$
P_{f s}=1-\exp \left[-A_{e}\left(\frac{{ }_{f}}{\sigma_{o s}}\right)^{m} s\right]
$$

Comparing Eqs. (18) and (20) where in both equations the maximum extreme fiber stress is used as the reference value, we conclude that for the same failure probability, 


\section{ORIGTINAL PAGE IS OF POOR QUALITY}

$$
\sigma_{o s}=\left(\frac{A_{e}}{C_{s}}\right)^{1 / m_{s}}
$$

In addition to determining $\sigma_{0}$ and $m_{s}$, the Sr.ARF nrnnram renuires knowledae of $\mathrm{k}_{\mathrm{o}}$. Assumina shear-insensitive fracture, Eq. (11) cañ be substituted into $\mathrm{Eq}$. (7) to obtain

$$
P_{s S}=\exp \left[-\int d A \int_{0}^{\sigma}\left(\frac{2}{\pi} \cos ^{-1} \sqrt{\frac{\sigma_{c r}}{\sigma_{1 s}}}\right) \frac{d N}{d \sigma_{c r}} d \sigma_{c r}\right]
$$

Taking the natural $\log$ of $\mathrm{Eq}$. (22) and integrating by parts yields

$$
\ln P_{s S}=-\frac{A_{e}}{\pi} \int_{0}^{\sigma} 1 s \frac{N_{s}\left(\sigma_{c r}\right)}{\sqrt{\sigma_{c r}} \sqrt{\sigma_{1 s}-\sigma_{C r}}} d \sigma_{c r}
$$

where $A_{e}$ is given by Eq. (19) $\left(A_{e} \approx w L\right.$ ?) for the four-point bend specimen. Equation (23) is an Abel integral equation with the solution (Batdorf and Chang, 1977)

$$
\begin{array}{r}
A_{e} N_{s}\left(\sigma_{c r}\right)=-2 \sqrt{\sigma_{c r}} \int_{0}^{\sigma} \frac{d^{2}}{d \sigma_{1 s}^{2}}\left[\ln _{s s}\left(\sigma_{1 s}\right)\right] \\
\times \sqrt{\sigma_{c r}-\sigma_{1 s}} d \sigma_{1 s}
\end{array}
$$

From Eq. (18) with $\sigma 1 s=\sigma_{f}$ as the reference stress

$$
\frac{d^{2}}{d \sigma_{1 s}^{2}}\left[\ln P_{s s}\left(\sigma_{1 s}\right)\right]=m_{s}\left(m_{s}-1\right)\left[-c_{s} \sigma_{s} m^{-2}\right]
$$

Introducing a new variable $n$ defined as $\eta=\left(2 \sigma / s / \sigma_{c r}\right)-1$ and substituting Eq. (25) into Eq. (24), we obtain

$$
\begin{gathered}
N_{s}\left(\sigma_{c r}\right)=\frac{2^{3 / 2-m_{s}} c_{s} m_{s}\left(m_{s}-i\right) \sigma_{c r} m_{s}}{A_{e}} \int_{-1}^{1} \\
\times(1+n)^{m_{s}-2}(1-n)^{1 / 2} d n
\end{gathered}
$$

Now from Eq. (21) $C_{S}=A_{e^{\sigma}}^{-m_{s}}$, and consequently $C_{S}$ and $A_{e}$ can be eliminated from Eq. $(26)$ and $\sigma_{0 S}$ used instead. Since $N_{s}\left(\sigma_{c r}\right)=k_{B s} \sigma_{c r}, k_{B s}$ can be evaluated by numerically integrating Eq. (26) using Gaussian quadratures. Since aos is used, the effective area given by Eq. (19) is inherent in $N_{s}\left(\sigma_{c r}\right)$. It is interesting to note that $N_{\mathrm{s}}\left(\sigma_{\mathrm{cr}}\right)$ can be determined more easily from equibiaxial tensile tests since for $\sigma_{1 s}=\sigma_{2 s}=\sigma_{n s}=\sigma, \omega / \pi=1.0$ and

$$
N_{s}\left(\sigma_{c r}\right)=-\frac{1}{A_{e b}} \ln P_{s s}=\frac{C_{s}}{A} \sigma_{e b} \sigma_{c r}=k_{B s} \sigma_{c r}^{m_{S}}
$$

where $A$ ob is the effective equibiaxially loaded tensile area and the equibiaxial failure rate is assumed to also follow Eq. (18). When using the least squares method with $\mathrm{Eq}$. (18) to evaluate $\mathrm{C}_{\mathrm{s}}$ and $m_{s}$, $P_{f s}$ can be determined from ranked fracture stress data using the simple equation

$$
P_{f s}\left(\sigma_{j s}\right)=\frac{j}{N+T}
$$

where $\mathrm{N}$ is the total number of uniaxial or equibiaxial tests and $j$ is the rank of the surface fracture stress $\sigma_{j s}$.

EXAMPLE

In order to test the surface crack distributed reliability analys is in SCARE, several example problems were analyzed from the open literature. In addition, the rotationally loaded, silicon nitride annular disk (Gyekenyesi, 1986) was reanalyzed assuming that fractures in the MOR bars as well as the disks were caused by surface flaws. The Weibull modulus $m_{s}$ was set equal to $m=7.65$ as before, but the previously used, volume $f l a w$ based scale parameter $\sigma_{0}$, was readjusted so that $P_{f}=P_{f s}$ in the MOR bars, when both are loaded in uniform tension. As a result of this requirement, we obtain for the four-point bend specimen that,

$$
\sigma_{O S}=\left(\frac{A_{e}}{V_{e}}\right)^{1 / m_{s}} \sigma_{0}=\left[\frac{2\left(m_{s} w+w+h\right)}{w h}\right]^{1 / m_{s}} \sigma_{0}
$$

From Gyekenyesi $(1986), \sigma_{0}=74.82 \mathrm{MPa} \mathrm{m}^{0.3922}$ $(45,800$ psi in. 0.3922) and the "A-size" test bars had dimensions of $w=0.635 \mathrm{~cm}(0.25$ in. $), h=0.3175 \mathrm{~cm}$ (0.125 in.), $L_{1}=1.905 \mathrm{~cm}(0.75$ in. $)$ and $L_{2}=0.9525 \mathrm{~cm}(0.375 \mathrm{in.})$. $A_{e}$ is given by Eq. (19) and $V_{e}$ is the effective volume in four-point bending, that is

$$
v_{e}=\frac{w h}{2}\left[\frac{L_{1}+m_{s} L_{2}}{\left(m_{s}+1\right)^{2}}\right]
$$

Using the given data in Eq. (29), we obtain that $\sigma \mathrm{s}=232.0 \mathrm{MPam} 0.2614(87,891 \mathrm{ps} i$ in. 0.2614$)$. The dimensions of the disk are given in Fig. 5 , and the same MSC/NASTRAN analys is was performed as for volume flaws with the exception that shell elements were added to identify external surfaces, to calculate their areas and to identify appropriate surface stress states. Reliability calculations were made at various speeds using several surface crack fracture models. Selected results from these analyses are shown in Fig. 5 and Table II. For a given speed, failure probabilities are considerably less than those obtained by Gyekenyesi (1986) for all fracture models, indicating that failure was most likely due to volume flaws as originally concluded. Obviously, the main reason for the greatly decreased failure estimates is the much $h$ igher equivalent surface Weibull scale parameter $\sigma_{0}$. Results for the shear-sensitive Griffith crack and notch were practically identical, with the notch being slightly more shear-sensitive as expected. The importance of post-mortem fractography to identify the nature of the fracture causing flaws is evident from the two widely different set of answers obtained for the same problem. Furthermore, the difference between predictions from various available surface crack fracture theories for a specified loading is considerably 
less than the difference found in volume flaw based failurc models.

In addition to comparing surface and volume flaw based analyses for the same ceramic structure, failure probability was calculated for a transversely loaded circular alumina disk and compared to data obtained by Brockenbrough et a1. (1985). This data consisted of calculated failure probabilities obtained from using Batdorf's shear-insenitive fracture theory in conjunction with the finite element analys is code ANSYS. The selected disk had an outside radius $r_{0}=25 \mathrm{~mm}$ (0.984 in.), a thickness of $t=2.5 \mathrm{~mm}(0.098$ in.), was loaded by a circular line load at $r=1.5 \mathrm{~mm}$ (0.059 in.) and was simply supported at a radius of $22 \mathrm{~mm}(0.866 \mathrm{in.})$. After matching the stress solutions for a given load from the two different finite element codes (MSC/NASTRAN and ANSYS), the failure probabilities were calculated at various loads. Typically, to obtain a $P_{f s}=0.50$, SCARE2 predicted a total line load of $1105 \mathrm{~N}(248.3 \mathrm{lb})$, while according to Brockenbrough et al. (1985) (corrected version) a line load of approximately $1130 \mathrm{~N}(253.9 \mathrm{lb})$ had to be applied, showing good agreement between the two load predictions.

\section{CONCLUSIONS}

The general purpose, statistical, fast fracture failure probability code SCARF has been enhanced to include the possibility of failure due to two concurrent but not interacting flaw populations. In addition, reliability analysis with linear finite elements is now also possible. The program includes a number of widely used polyaxial fracture models, appropriate extreme value statistics and the ability to calculate material failure distribution parameters for both volume and surface distributed flaws. Current work includes the planned addition of more advanced increasingly shear-sensitive failure criteria which permit out-of-plane crack extension for both types of imperfections. In addition, the influence of bimodal flaw populations on individual material parameters, throuqh censored data analysis, needs to be determined. Finally, the problem of a transversely loaded circular plate will be anewly studied to resolve some of the contradictory trends reported by Ruf in et a 1. (1984) and Shetty et al. (1984).

\section{REFERENCES}

1. Batdorf, S.B., "Fundamentals of the Statistical Theory of Fracture," Fracture Mechanics of Ceramics, Vol. 3-Flaws and Testinq, R.C. Bradt, D.P.H. Hasselman, and F.F. Lange, eds., Plenum Press, 1978, pp. 1-30.

2. Batdorf, S.B., "Fracture Statistics of Isotropic Brittle Materials with Surface Flaws," Air Force Systems Command, Air Force Rep. No. SAMS0-TR-73-378, 1973.

3. Batdorf, S.B., and Chang, D.J., "On the Relation Between the Fracture Statistics of Volume Distributed and Surface Distributed Cracks," University of California at Los Angeles, UCLA-ENG-7723, Feb. 1977.
4. Batdorf S.B., and Heinisch, H.L. Jr., "Fracture Statistics of Brittle Materials with Surface Cracks," Engineering Fracture Mechanics, Vol. 10, No. 4,1978 , pp. 831-841.

5. Brockenbrough, J.R., Forsythe, L.E., and Rolf, R.L., "Reliability of Brittle Materials in Thermal Shock," Alcoa Laboratories, AL Rep. No. 52-85-22, 1985.

6. Govila, R.K., "Statistical Strength Evaluation of Hot-Pressed $\mathrm{Si}_{3} \mathrm{~N}_{4}$, American Ceramic Society Bulletin, Vol. 62, No. 11, Nov. 1983, pp. 1251-1258.

7. Gyekenyesi, J.P., "SCARE: A Postprocessor Program to MSC/NASTRAN for Reliability Analysis of Structural Ceramic Components," Journal of Engineering for Gas Turbines and Power, Vol. 108, No. 3, JuTy 1986, pp. 540-546.

8. Johnson, C.A., "Fracture Statistics of Multiple Flaw Distributions," Fracture Mechanics of Ceramics, Vol. 5-Surface Flaws, Statistics, and Microcracking, R.C. Bradt, A.G. Evans, D.P.H. Hasselman, and F.F. Lange, eds., Plenum Press, New York, 1983, pp. 365-386.

9. Paluszny, A., and Wu, W., "Probabilistic Aspects of Designing with Ceramics," Journal of Enqineering for Power, Vol. 99, No. 4, Oct. 1977, pp. $617-630$.

10. Petrovic, J.J., "Mixed-Mode Fracture of HotPressed $\mathrm{Si}_{3} \mathrm{~N}_{4}, "$ Journal of the American Ceramic Society, Vol. 68, No. 6, June 1985, pp. 348-355.

11. Rufin, A.C., Samos, D.R., and Bollard, R.J.H. "Statistical Failure Prediction Models for Brittle Materials," AIAA Journal, Vol. 22, No. 1, Jan. 1984, pD. 135-140.

12. Samos, N.R., "Experimental Investigation and Probability of Failure Analys is of Pressure Loader Alumina Discs," M.S. Thesis, University of Washinqton, 198 ?

13. Shetty, D.K., Rosenfield, A.R., and Duckworth, W.H.,

"Statistical Analysis of Size and Stress State Effects on the Strength of an Alumina Ceramic," Methods for Assessing the Structural Reliability of Brittle Materials, ASTM-STP-844, S.W. Freiman and C.M. Hudson, eds., American Society for Testing and Materials, Philadelphia, PA, 1984 , pp. $57-80$.

14. Weibu11, W., "A Statistical Theory of the Strength of Materials," Ingeniors Vetenskans Akademien Handl inger, No. $151,1939$.

15. Wertz, J.L., and Heitman, P.W., "Predicting the Reliability of Ceramic Turbine Components, " Advanced Gas Turbine Systems for Automobiles, SAE-SP-465, Society of Automotive Enqineers, 1980 , pp. 69-77. 
TABLE I. - FORMS OF $P_{2 S}$ FOR VARIOUS SHEAR-SENSITIVE FRACTURE CRITERIA AND SELECTED SURFACE CRACK CONFIGURATIONS ( $\sigma_{\mathrm{nS}}$ IS TENSILE)

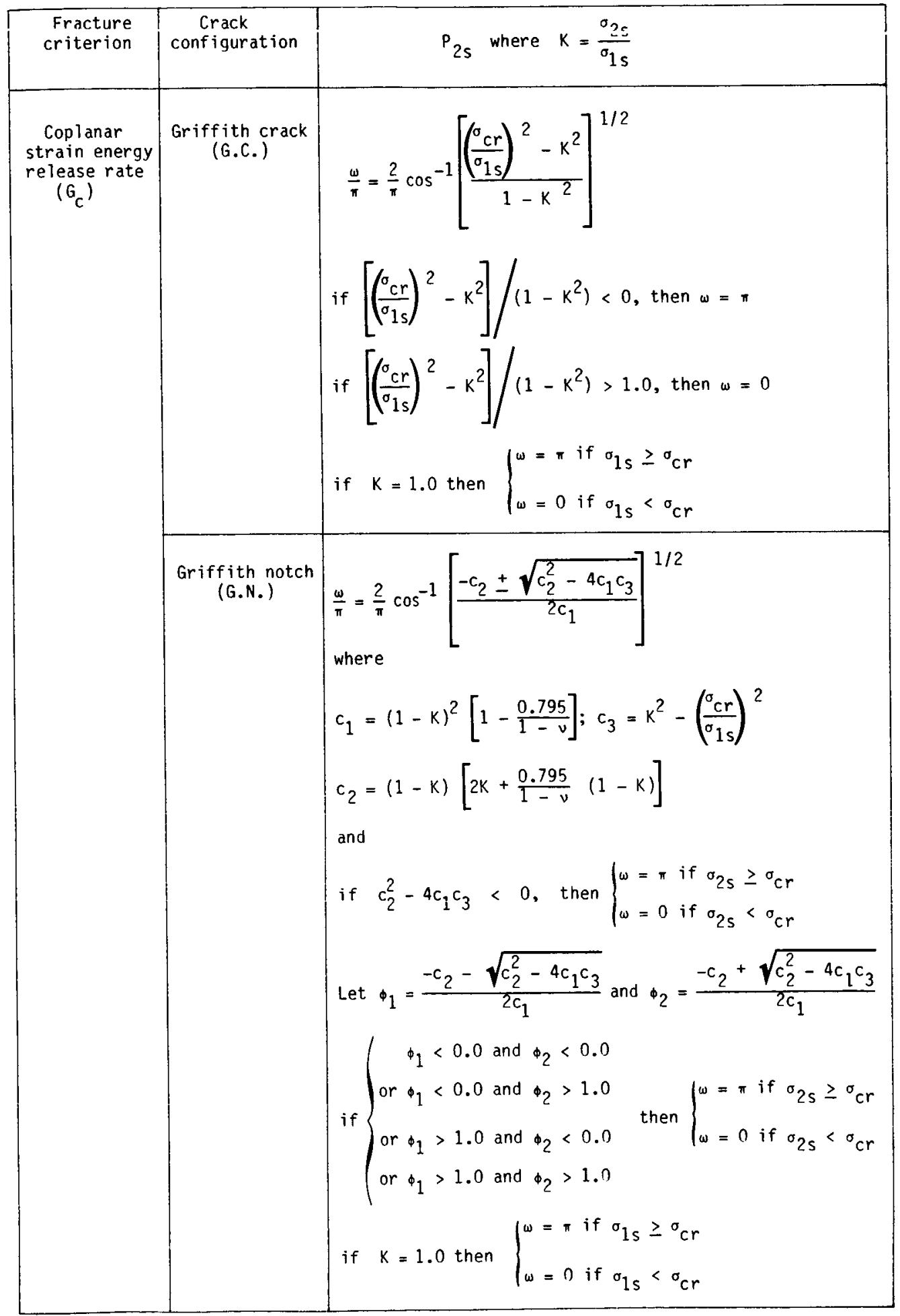


TABLE II. - EXAMPLE I FAILURE PROBABILITIES AS A FUNCTION OF ROTATIONAL SPEED FOR VARIOUS FRACTURE MODELS

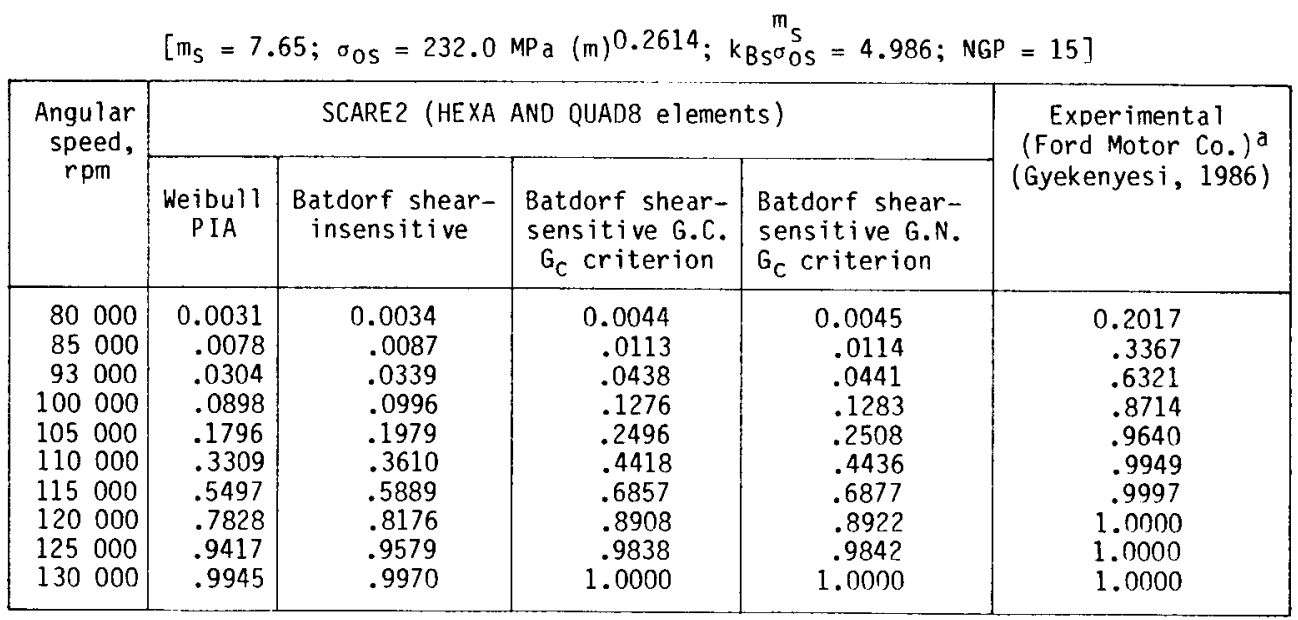

G.C. - Griffith crack

G.N. - Griffith notch

aExperimental data fitted to a Weibull equation and calculated at the speeds shown. 
"ELEM IS ONLY

CALLED ONCE

PER PROGRAM

EXECUTION

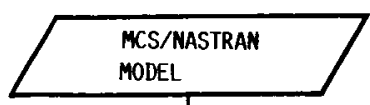

MODEL
ORIGINAL PAGE IS

OF POOR QUALITY
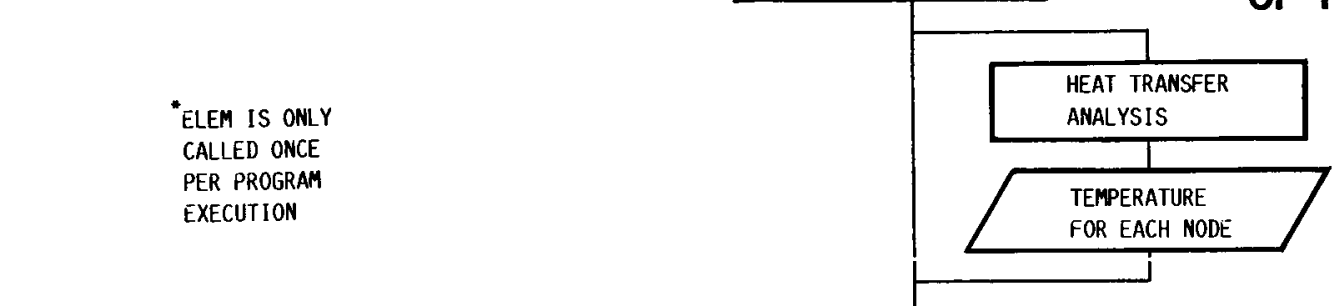

HEAT TRANSFER

FOR EACH NODE

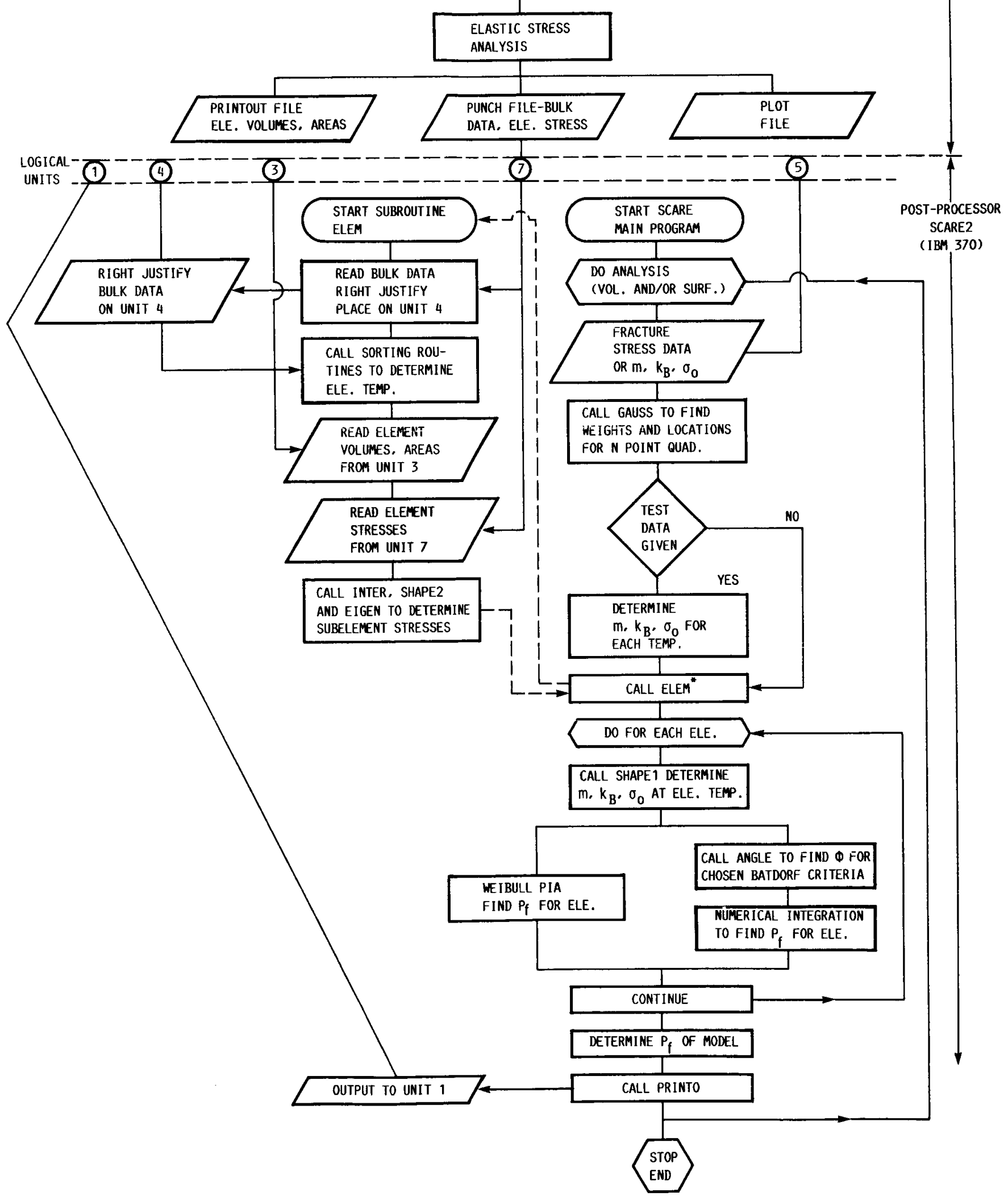

Figure 1. - Computational elements of the SCARE2 Reliability analysis program. 


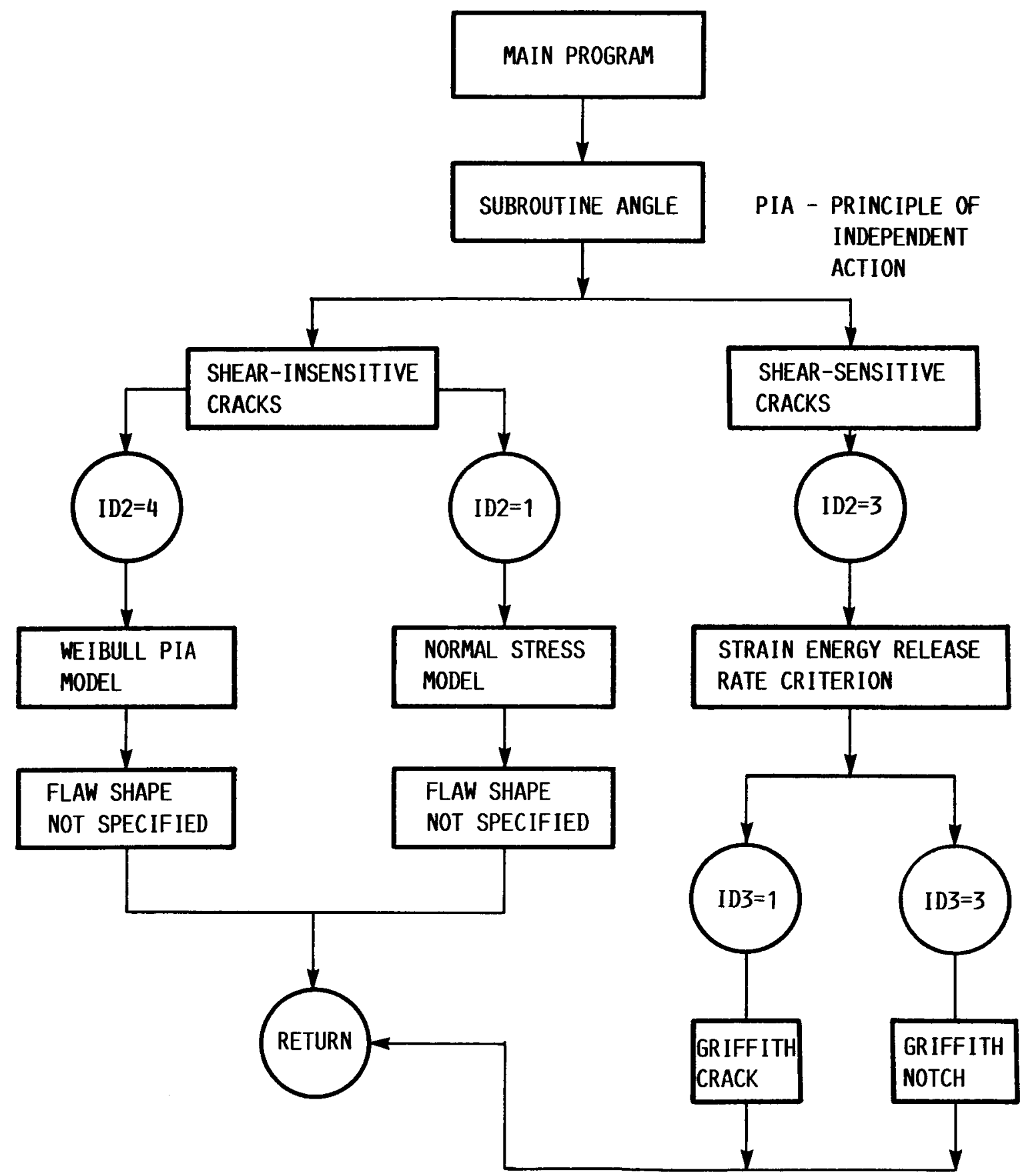

FigURE 2. - FLOWCHART FOR SUBROUTINE ANGLE BASED ON SURFACE FLAW FRACTURE ANALYSIS. 


\begin{tabular}{|c|c|c|}
\hline COLUMNS & VARIABLE & ENTRY AND DESCRIPTION \\
\hline $1-5$ & ID1 & $\begin{array}{l}\text { CONTROL INDEX FOR EXPERIMENTAL DATA } \\
\text { 2: 4-PT. BENDING TEST DATA } \\
\text { 3: ALL THE MATERIAL PARAMETERS } \mathrm{m}_{\mathrm{s}^{\prime}} \sigma_{\mathrm{OS}^{\prime}} \\
\overline{\mathrm{k}}_{\mathrm{BS}} \text { ARE KNOWN AS INPUT }\end{array}$ \\
\hline $6-10$ & ID2 & $\begin{array}{l}\text { CONTROL INDEX FOR FRACTURE CRITERIA } \\
\text { 1: SHEAR-INSENSITIVE, NORMAL STRESS } \\
\text { CRITERION } \\
\text { 3: TOTAL ENERGY RELEASE RATE CRITERION } \\
\text { 4: WEIBULL PIA SHEAR-INSENSITIVE MODEL }\end{array}$ \\
\hline $11-15$ & ID3 & $\begin{array}{l}\text { CONTROL INDEX FOR CRACK SHAPES } \\
\text { 1: GRIFFITH TYPE CRACK } \\
\text { 3: GRIFFITH NOTCH TYPE CRACK }\end{array}$ \\
\hline $16-20$ & ID4 & $\begin{array}{l}\text { CONTROL INDEX FOR TYPE OF ANALYSIS } \\
\text { 1: VOLUME FLAW BASED FRACTURE ANALYSIS } \\
\text { 2: SURFACE FLAW BASED FRACTURE ANALYSIS } \\
\text { 3: BOTH VOLUME AND SURFACE FLAW BASED } \\
\text { FRACTURE ANALYSIS }\end{array}$ \\
\hline $21-25$ & IPRINT & $\begin{array}{l}\text { CONTROL INDEX FOR PRINTING STRESSES } \\
\text { 1: DO NOT PRINT ELEMENT STRESSES } \\
\text { 0: PRINT ELEMENT STRESSES }\end{array}$ \\
\hline \multicolumn{3}{|c|}{ END OF FIRST CARD OR STATEMENT NUMBER ONE } \\
\hline \multicolumn{3}{|c|}{ BEGINNING OF SECOND CARD OR STATEMENT NUMBER TWO } \\
\hline $1-5$ & NE & NUMBER OF TOTAL HEXA AND PENTA ELEMENTS \\
\hline $6-10$ & NH & NUMBER OF HEXA ELEMENTS USED \\
\hline $11-15$ & NP & NUMBER IF PENTA ELEMENTS USED \\
\hline $16-20$ & NES & NUMBER OF TOTAL QUAD8 AND TRIA6 ELEMENTS \\
\hline $21-25$ & NSQ & NUMBER OF QUAD8 ELEMENTS USED \\
\hline $26-30$ & NST & NUMBER OF TRIA6 ELEMENTS USED \\
\hline $31-35$ & NA & $\begin{array}{l}\text { NUMBER OF TRIAX6 ELEMENTS USED IN THE MODEL } \\
\text { (VOLUME FLAW ANALYSIS ONLY) }\end{array}$ \\
\hline $36-40$ & NT & $\begin{array}{l}\text { THE NUMBER OF TEST SPECIMENS AT A GIVEN } \\
\text { TEMPERATURE }\end{array}$ \\
\hline $41-45$ & NGP & NUMBER OF GAUSSIAN QUADRATURE POINTS \\
\hline $46-50$ & NS & $\begin{array}{l}\text { NUMBER OF SEGMENTS REQUIRED TO FORM THE } \\
\text { ENTIRE STRUCTURE }\end{array}$ \\
\hline $51-55$ & JT & $\begin{array}{l}\text { NUMBER OF TEST TEMPERATURES AT WHICH } \\
\text { MATERIAL DATA IS SPECIFIED }\end{array}$ \\
\hline $56-60$ & LONL & $\begin{array}{l}\text { CONTROL INDEX FOR SELECTING USE OF LINEAR } \\
\text { OR NONL INEAR (QUADRATIC) ELEMENTS } \\
\text { 0: ONLY LINEAR ELEMENTS ARE USED IN THE } \\
\text { MODEL } \\
\text { 1: ONLY QUADRATIC ELEMENTS ARE USED IN } \\
\text { THE MODEL }\end{array}$ \\
\hline
\end{tabular}

FIGURE 3. - SCARE SURFACE FLAW BASED ANALYSIS MASTER CONTROL DECK DATA REQUIREMENTS. 


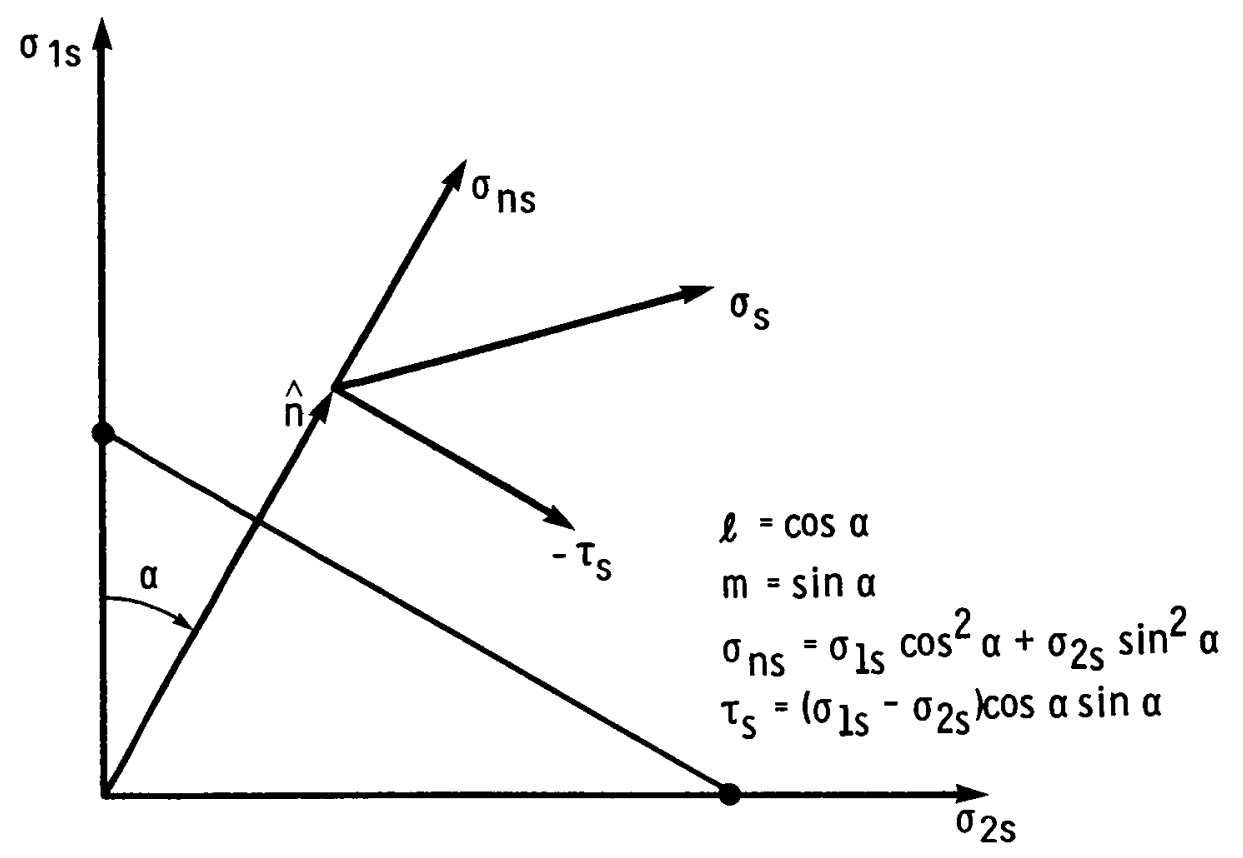

Figure 4. - Stresses ON THE REDUCED PLANE-STRESS CAUCHY INF INITESIMAL TETRAHEDRON IN PRINCIPAL STRESS SPACE. 


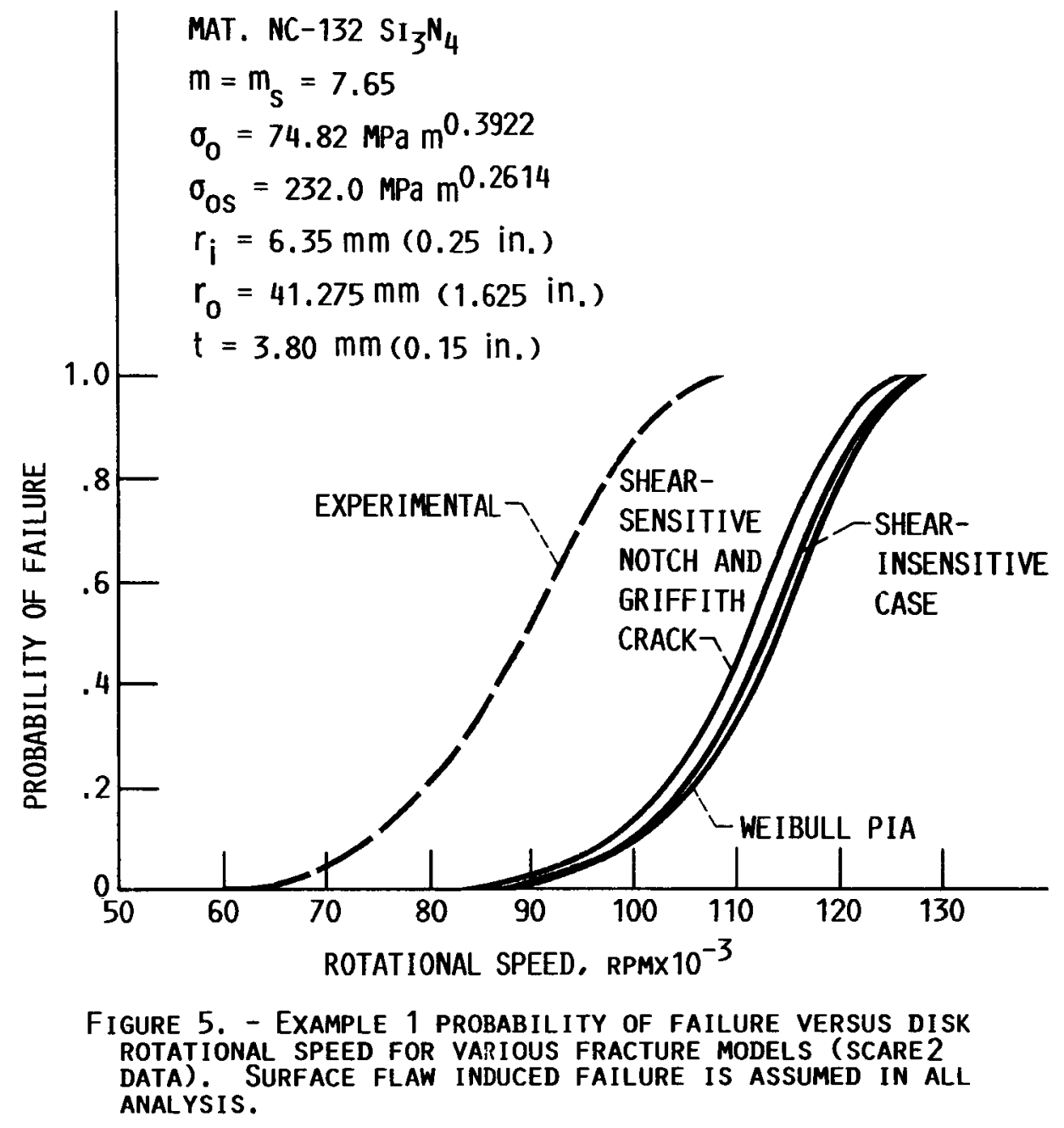




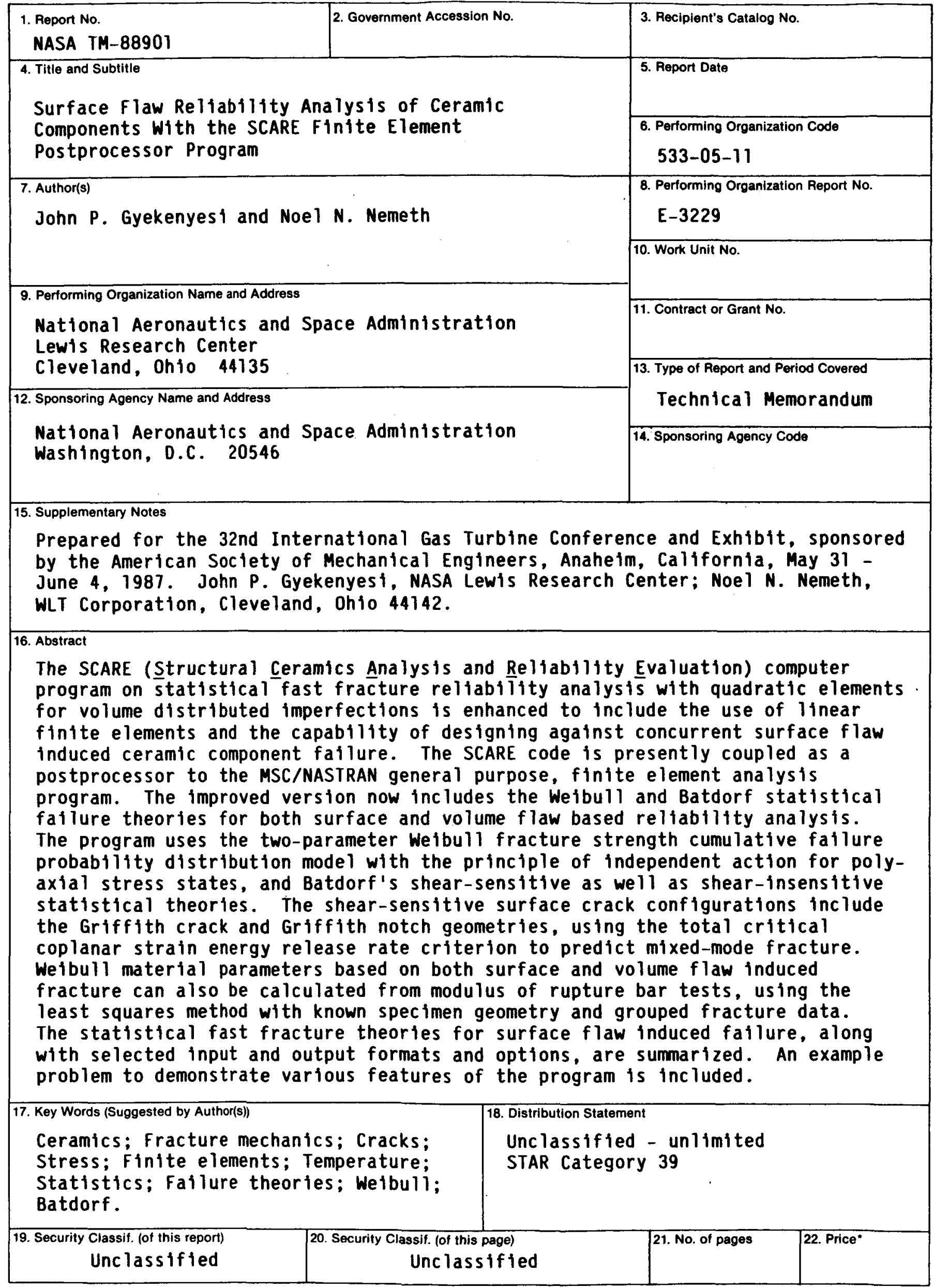

"For sale by the National Technical Information Service, Springfield, Virginia 22161 